1

2

3

4

5

6 7

8

9

10

11

12 13

14

15

16

17 14 15 16

\title{
Strong etching formulation (time and rate) for PADC with deep depth bulk
}

\section{etch rate study}

M.A. Al-Jubbori ${ }^{1, *}$, M. Fromm², E.M. Awad ${ }^{3}$

${ }^{1}$ Department of Physics, College of Education for Pure Sciences, University of Mosul, 41001 Mosul, Iraq

${ }^{2}$ Laboratoire Chrono-Environnement, UMR CNRS 6249, Université de Bourgogne Franche-Comté, 16 route de Gray, F-25030 Besançon Cedex, France

${ }^{3}$ Physics Department, Faculty of Science, Menoufia University, Shebin El-Koom, Menoufia 32511 Egypt

*corresponding author e-mail: mustaq_phy8@yahoo.com ; mushtaqphy8@gmail.com; mushtaq_phy@uomosul.edu.iq (MushtaqAl-Jubbori)

(1)




\section{Abstract}

Aqueous $\mathrm{NaOH}$ with ethanol (strong) etchant is widely used. It shortens etching time effectively compared to normal etching conditions $(6.25 \mathrm{~N} \mathrm{NaOH}$ at $\left.70{ }^{\circ} \mathrm{C}\right)$. Two equations have been proposed to calculate the etching time with $\mathrm{NaOH}$ molarity and ethanol volume. Another two empirical equations were introduced for estimating the bulk etch rates of PADC etched in strong etchant. Up to now, there were no such equations available in the literature that can predict etching time and $\mathrm{V}_{\mathrm{b}}$ of PADC with etchant molarity and ethanol volumes. The proposed equations were compared to fundamental $\mathrm{V}_{\mathrm{b}}$ models stemming from literature. Fast etching enables the follow-up of bulk etch rate variation versus depth in the detector material up to $\approx 80 \mu \mathrm{m}$. In agreement with previous studies, an equation is given which allows such variations to be expressed under the form of a reciprocal bulk etch rate normalized to depth (i.e., removed layer).

Keywords:

PADC; Soft/strong etching; Arrhenius model; Multi-hit model; Bulk etch rate; Etching time. 


\section{Introduction}

The standard procedure when using solid-state nuclear track detectors (SSNTD) is to reveal latent ion tracks by operating a chemical etching which makes them visible under the optical or atomic force microscope. Commonly used etching solutions in the literature are alkaline etchant such as $\mathrm{NaOH}$ or $\mathrm{KOH}$ with concentration range of 6-7 $\mathrm{N}$ at temperatures of $60-70{ }^{\circ} \mathrm{C}$ [1-10]. However, a new etchant solution composed of $\mathrm{NaOH}$ with different amounts of alcohols (ethanol and/or methanol) has been used as a strong and active etchant [11-13]. Such mixtures are very effective in reducing the time needed to reveal and measure diameters of alpha tracks. Strong etching was found to provide a quadratic function of growing alpha particle tracks diameter with etching time. So, the strong etching can reduce the etching time by factor " 4 ", and thus enhance the etching time [13]. Processing many detectors can be time-consuming using normal etching compared to strong one. Therefore, it requires fine-tuned analyses for better understanding and use in routine work.

Poly-allyl-diclycol-carbonate (PADC) is mainly made of the monomer allyldiclycol-carbonate (ADC). ADC chemical structure contains two carbonate groups and one ether function. Its alkaline dissolution results in the loss of the carbonate groups from the residual molecule (see next section). This process is activated in the presence of hydroxyl ions available in an alkali solution (alkaline hydrolysis). 
The reaction is endothermic i.e., the process needs energy to be initiated and its rate increases with increasing temperature of the solution. In principle, two models were used to describe chemical etching process. The first one is Arrhenius model, accounting thermodynamic equilibrium of chemical reaction between educts and products in homogeneous phase. In this statistical consideration, the bulk etch rate can be determined as a function of etchant concentration (C), temperature (T), as follows [14]:

$$
V_{b}(C, T, B, n, \varepsilon)=B C^{n} e^{\frac{-\varepsilon}{k T}}
$$

Where, $B$ is the normalization constant, the power $n$ (not necessary integer) indicates the chemical reaction order and the activation energy $\varepsilon(\mathrm{eV})$ are the adjustable parameters. $k$ is Boltzmann's constant. Its results are widely used as well as accepted $[15,16]$. From this model, only two important parameters are deduced: the order of chemical etching (n) and the activation energy of etching (ع).

The second is Multi-hit model (MHM, also known as v-hit) [17], in which the dissolution of the bulk material described by the number of hits $(v)$ between the molecules of etchant and detector. The model is thus combining hits frequency with thermodynamic equations for a simultaneous interpretation of chemical reactions and diffusion processes. The basic idea of this model is to claim that the processes are initiated by single or repeated interactions or hits of the target 
(molecules, molecular fragments, emulsion grains and/or living cells). SSNTDs are then considered as composed of sensitive nanometric volumes $(S N V)$ and such $S N V$ can switch from the state "No" to the etched state "Yes" after etching process with a certain probability. Poisson's distribution describes this probability as below:

$$
P_{v}(\xi)=1-\sum_{k=1}^{v-1} \frac{\xi^{k}}{k !} e^{-\xi}
$$

These centres are etched if they suffer a fluctuating number of hits, $v$ at the nanometre scale by etchant molecules greater than some threshold value of $v$. Parameter $(\xi)$ represents the average number of hits per sensitive volume. Several functions for bulk etch rate proposed in terms of multi-hit approximation [17]. In the present study, the focus was on the effect of etchant concentration on etching rate. Therefore, two modules were considered (where the concentration effect is dominant) to calculate the detector bulk etch rate. Module 8 of multi-hit, we will call it MHM-M8, in which $\xi=\frac{C}{C_{0}}$ and module 15 in which $\xi=\frac{C}{C_{0}} e^{\frac{\varepsilon}{k T}}$, we will call it MHM-M15. More information about this model can be found in [18-22] and references therein. MHM-M8 bulk etch rate can be written as:

$$
V_{b}\left(C, T, B, v, \varepsilon, c_{0}\right)=B C e^{\frac{-\varepsilon}{K T}} P_{v}\left(\frac{C}{C_{0}}\right)
$$

While bulk etch rate with MHM-M15 is as follows: 


$$
V_{b}\left(C, T, B, v, \varepsilon, c_{0}\right)=B C e^{\frac{-\varepsilon}{K T}} P_{v}\left(\frac{C}{C_{0}} e^{\frac{\varepsilon}{k T}}\right)
$$

Many physical parameters can be deduced from this model, n, $\varepsilon$ and number of hits

99

100

101

102

103

104

105

106

107

108

109

110

111

112

113 necessary to activate the reaction between etchant molecules and detector molecules $(v)$. Etching process is envisioned as a macroscopic process when described by those two models; however, much information about etching processes at the microscopic scale were ignored (see etching mechanism section).

Many empirical equations have been used to calculate bulk etch rates as function of both $\mathrm{C}$ and $\mathrm{T}$ [23], such as for example:

$$
V_{b}\left(a_{1} \mid a_{5}\right)=a_{1} 10^{\left(a_{2} C+a_{3} T-a_{4} C T-a_{5}\right)}
$$

Where $a_{1}$ to $a_{5}$ are free adjusting parameters.

Recently, another equation assigned in terms of the etchant concentration (C), and free adjusting (a) and (b). This equation (referred here as Al-Jubbori2016) was proposed in [5] as follows:

$$
V_{b}=a\left(e^{b C}-1\right)
$$

Nevertheless, since the involvement of the strong etching ( $\mathrm{NaOH}$ plus ethanol) in 2005 [11] no equation was found to predict such specific bulk etch rates as a 
114 function of the etchant concentration $\mathrm{C}$ at different ethanol fractions. Thus, the aim 115 of the present work is to introduce a new empirical equation that can predict the 116 etching time and the bulk etch rate in a wide $\mathrm{NaOH}$ concentration range $(2-22 \mathrm{~N})$ of 117 different ethanol volume of $0,1,2$ and $3 \mathrm{~mL}$ (corresponding to 0,11, 20 and $27 \%$ 118 volume fraction) that was added to $8 \mathrm{~mL}$ of aqueous $\mathrm{NaOH}$ solutions. 119 Additionally, an explanation to the rigorous bulk etch rate mechanism and the 120 significant reduce in etching time by strong etching is proposed. Strong etching is 121 used to investigate the bulk etch rate to deeper depth layers up to $80 \mu \mathrm{m}$ or more. 122 Besides, a reciprocal bulk etch rate equation is going to be deduced and compared 123 with those of literature data.

\section{Etching Mechanism}

Since its discovery in 1978 [24], PADC (also known as CR-39 ${ }^{\mathrm{TM}}$ ) is considered as one of the most successful SSNTD for detection of charged particles with linear

127 energy transfer greater than $10 \mathrm{keV} / \mu \mathrm{m}$ (in water) [25]. It is a highly cross-linked thermoset polymer. Soft $\left(\mathrm{NaOH} / \mathrm{H}_{2} \mathrm{O}\right)$ and strong $(\mathrm{NaOH} /$ ethanol) etching processes follow the same etching mechanism as illustrated in Figures 1-3. Etching takes place due to scission of the carbonate ester bond by hydroxide ions through basic hydrolysis of ester moiety (see Fig. 1). Electron rich hydroxide ions cause the

132 scission of ester linkage because carbonyl groups $(\mathrm{C}=\mathrm{O})$ are electrically polarized 
133 (the carbon atom site is electron deficient). Electron transfer occurs thus from 134 electron rich region to electron deficient region, so that, $\mathrm{OH}$ groups will attack 135 electron deficient ones (carbonyl group) as shown in Fig. 2. In PADC there are 136 four possible positions which are subjected to cleavage by the hydroxide ion [26] 137 as shown in Fig. 3. Etching of PADC in $\mathrm{NaOH} /$ ethanol will fierce bulk etch rate of 138 the detector compared to $\mathrm{NaOH} /$ water. This may likely be due to the better 139 reactivity during etching and presumably to a better solubilization of organic etch140 products released from PADC. Relative static permittivity (which provides a 141 measure of polarity) of pure methanol or ethanol are respectively 33 and 24 at $14225^{\circ} \mathrm{C}$, with quasi-identical dipolar moments of $\approx 1.70$ debye $(\mathrm{D})$; as water has a 143 relative static permittivity of typically 75 at $25^{\circ} \mathrm{C}\left(64\right.$ at $\left.70^{\circ} \mathrm{C}\right)$ and a slightly higher 144 dipolar moment of $\approx 1.85 \mathrm{D}$ [27]. A decrease of the dielectric constant (i.e., of the 145 relative static permittivity) of a given medium has a direct consequence on both 146 reactivity and miscibility. In media containing methanol or ethanol, the dielectric 147 constant is small, therefore attraction forces between electrical charges are 148 enhanced in comparison to pure water. It is therefore likely that addition of 149 alcohols in $\mathrm{NaOH}$ aqueous solution may partly lower the relative static permittivity 150 value of the etchant and thus it can enhance hydroxide ion reactivity on polar 151 groups (carbonate ester groups). 
Fig. 3 shows that etch-products are mainly: saturated, unsaturated alcohols and

carbonate ions, the latter being strongly miscible in water. The basic solubility rule states that "like dissolves like" but when applied to alcohols things become a bit more complex. Alcohols are sparingly soluble in water; their solubilities decrease with carbon chain length. Higher alcohols are insoluble in water. Organic alcohols consist of a carbon chain (always non-polar) and a $\mathrm{OH}$ group (which is polar). It is well-known for example that after $7^{\text {th }}$ carbon atoms in a chain (i.e. for homologues longer or equal to heptanol), alcohols are considered immiscible in pure water. By mixing water and ethanol (or methanol), solubilities of both higher alcohols and aromatic hydrocarbons (non-polar in nature) increase in water/ethanol mixtures as the volume fraction of ethanol increases [27]. PADC etched products are thus more soluble in ethanol than in water. The decrease in etching time is therefore likely to be due to both of an enhancement of reactivity of the etchant (hydroxyl ions) and an increase in solubility of organic etch products resulting in an increase in the bulk etch rate, $\mathrm{V}_{\mathrm{b}}$.

\section{Experiment}

PADC detector sheet of thickness $650 \mu \mathrm{m}$, manufactured by American Acrylics (US), was used. Detector sheet aging more than 20 years old was cut to small pieces of area $1 \mathrm{~cm}^{2}$. Each piece was irradiated to fission fragments of ${ }^{252} \mathrm{Cf}$ 
172 for $30 \mathrm{~min}$. Aqueous solution of $8 \mathrm{ml}$ fresh $\mathrm{NaOH}$ with concentrations 2, 4, 6.25, 8 , $17310,12,14,16,18,20,22,25,27$ and $30 \mathrm{~N}$ were prepared, and different ethanol 174 volumes of $0,1,2$ and $3 \mathrm{ml}$ (equivalent to $0,11,20$ and $27 \%$ volume fractions) 175 were added to the $\mathrm{NaOH}$ solutions. The suggested equations ( 9 and 10) have tested 176 in both a limited $\mathrm{NaOH}$ concentration range $(2-10 \mathrm{~N})$ where most applications are 177 carried out and in an extended $\mathrm{NaOH}$ concentration $(2-22 \mathrm{~N})$ to show the capability 178 of the proposed equation. The etchant was kept at $70^{\circ} \mathrm{C}$ by a water bath to avoid 179 ethanol evaporation noting that pure ethanol boils and evaporates at $78{ }^{\circ} \mathrm{C}$ and in a 180 mixture of water and $\mathrm{NaOH}$ at $95{ }^{\circ} \mathrm{C}$. For more details about the experiment, please 181 refer to Awad et al., [8]. Etching time was varied for different etching conditions 182 to keep the removed bulk etch layer for each case close to $\approx 10 \mu \mathrm{m}$. It was done due 183 to the limited range $(\sim 20-25 \mu \mathrm{m})$ of fission fragments in PADC detectors. After 184 etching of exposed detectors, diameters of fission fragment tracks were manually measured using an optical microscope (OPTIKA B-1000BF-ALC, Italy). Measurement resolution of track diameters was $\pm 0.5 \mu \mathrm{m}$. The etching time necessary to obtain fission track diameter $\approx 18 \mu \mathrm{m}$ was determined at the different etching conditions. Largest diameter of 40 almost circular fission fragment tracks, $\mathrm{D}_{\mathrm{ff}}$ were manually selected as much as possible and drawn as a function of the etching time, $t_{e}$ to determine the bulk etch rate [28] if the linear dependence of $D_{f f}$ $\left(t_{e}\right)$ is applicable for all etching conditions [29]. 
SSNTDs were irradiated to normal incident high energy ions of $7 \mathrm{GeV} \mathrm{Si}$ at 193 Bevelac, Berkeley, USA with particles density $\approx 1000-2000$ particles $/ \mathrm{cm}^{2}$. The 194 detectors were cut perpendicularly to the detector surface into several pieces of area $1 \mathrm{~cm}^{2}$. Each piece was etched in strong etching solution $(8 \mathrm{~mL}$ of $18 \mathrm{~N}$ $\mathrm{NaOH}+1 \mathrm{~mL}$ ethanol) at $70^{\circ} \mathrm{C}$ for different successive etching times. Removed 197 layer, $\mathrm{h}$ was determined experimentally by measuring the change in detector 198 thicknesses using the optical microscope after the detector was mounted in its 199 edge. After etching, track cones shaped etch-pits were found by careful polishing 200 of the detector edge to produce ion's nuclear track profile for Si ions. The growth of the cone shaped etch-pits for Si tracks at one side of the detector were followed 202 at different etching times. From the track cone length (L) at every etching step and 203 the corresponding removed layer, the track etch rate $V_{t}$ was determined directly 204 [30-32]. For normally incident particle, the track etch rate at given removed layer, $\mathrm{h}$ can be deduced if the track etching started immediately at the detector surface 206 without delay. Thus, the time dependent track length is available by track profile 207 technique and track etch rate is given as:

$$
V_{t}(h)=\frac{d L(h)}{d t}+V_{b}
$$


microscopically using FTIR for new, medium age, and old detectors. It was proved that aging effect is not dominant and has minor effect on PADC specially for bulk and low $\gamma$-ray doses samples. Bulk etch rate of PADC (type PM-355) was found almost constant even after storage for a long time (about ten years) in air at room temperature in the absence of light in another study [34]. However, for a sample of age more than 12 years, the forecasted loss of sensitivity is about $2 \%$ per year.

\section{Data analysis}

\subsection{Data fitting method}

The non-linear fitting procedure was carried out by minimizing the $\chi^{2}$ distribution iteratively for all the considered equations. Iteration process is repeated many times using many seed numbers for the adjusted parameters till the lowest $\chi^{2}$ is achieved [8]. Try and error method was used to obtain the global minimization as much as possible. $\chi^{2}$ values depend on degree of freedom, DF, which refers to the maximum number of the logically independent values that have the freedom to vary in the data sample (equals the number of the experimental data points minus 1). In the present work, the significant levels $\alpha$ was taken as 0.05 . The fitting of the two models and the two equations are discussed accordingly. 

first one, the etching time $t_{\mathrm{e} 1}$ necessary to reveal $18 \mu \mathrm{m}$ diameter of fission tracks is given in terms of the etchant concentrations as follows:

$$
t_{e 1}=\frac{G}{C^{q}}
$$

Where $\mathrm{q}$ is a dimensionless adjusting parameter and $\mathrm{G}$ is a normalization etching time factor of dimension $\left[\mathrm{min} \mathrm{mol}^{\mathrm{q}} \mathrm{L}^{-\mathrm{q}}\right]$. In the second one, the etching time $\mathrm{t}_{\mathrm{e} 2}$ is given as a function of $\mathrm{NaOH}$ molarity and ethanol fraction, $\mathrm{x}$ as follows:

Where $\mathrm{x}$ is the amount of ethanol volume, thus a and $\mathrm{x}$ are in $\mathrm{L}$ (litre) and $\mathrm{C}$ is the molar concentration $\frac{\mathrm{mol}}{\mathrm{L}}$ with $\mathrm{b} \neq 1$, then $\mathrm{K}$ has the following unit $\left[\frac{\mathrm{min}}{\mathrm{L}} \cdot\left(\frac{\mathrm{mol}}{\mathrm{L}}\right)^{b}\right]$. The physical meaning of the adjusting parameters could be deduced from their physical dimensions. However, due to their phenomenological nature, the physical

245 meaning of the current parameters is not straightforward. At least a meaning could 246 be deduced from their physical dimensions; such an attribution remains 247 nevertheless hypothetically. $\mathrm{K}$ is thus simply a scaling time constant. 
The present work is suggesting two bulk etch rate equations. In the first one, bulk etch rate $\left(\mathrm{V}_{\mathrm{b} 1}\right)$ was treated as a bulk quantity without considering the added ethanol fraction, like literature ones. $\mathrm{V}_{\mathrm{b} 1}$ can be determined in terms of the etchant concentration, $\mathrm{C}$ as follows:

$$
V_{b 1}=Q e^{\left(\frac{C-i}{j}\right)^{2}}
$$

Where $Q$ is the bulk etch rate normalization factor of dimension $\left[\frac{\mu m}{h}\right]$, while $i$ and $j$ are two adjusting parameters have concentration dimension, $\left[\frac{\mathrm{mol}}{\mathrm{L}}\right]$.

As stated before, no formula has been suggested by researchers to predict the bulk etch rate as a function of $\mathrm{NaOH}$ concentration, $\mathrm{C}$ and amount of ethanol volume, $\mathrm{x}$ in the etchant. Therefore, a second bulk etch rate formula, $\mathrm{V}_{\mathrm{b} 2}$ is suggested as a function of $\mathrm{C}$ and $\mathrm{x}$ simultaneously as follows:

$$
V_{b 2}=U\left(a_{1}+x\right) \exp \left(\frac{C-a_{2}}{a_{3}}\right)^{2}
$$

Where $\mathrm{U}$ is a conversion adjusting factor of dimension $\left[\frac{\mu \mathrm{m}}{\mathrm{h}}\right]$, $\mathrm{x}$ is amount of added ethanol in $\mathrm{L}, \mathrm{C}$ is $\mathrm{NaOH}$ concentration. The free parameter $\mathrm{a}_{1}$ has dimension of [L] while both of $\mathrm{a}_{2}$ and $\mathrm{a}_{3}$ have concentration dimension $\left[\frac{\mathrm{mol}}{\mathrm{L}}\right]$. 
The reciprocal bulk etch rate using strong etching normalized to depth (by 268 taking the whole removed layer as $\mathrm{z}=1$ ) was obtained as follows:

$$
\frac{1}{V_{b}(z)}=f+g e^{-z}
$$

270 Where $f$ and $g$ are the reciprocal bulk etch rate factors of dimension of $\frac{h}{\mu m}$.

\section{Results and Discussion}

\subsection{Etching time}

274

Fig. 4 shows the variation of etching time with the different $\mathrm{NaOH}$ molarity for 275 soft and strong etching, respectively. Tables 1 and 2 compile the adjusting 276 parameters G and q of Eq. 8 and K, a and b of Eq. 9, respectively. From Fig. 4 and 277 278 time with exactly same accuracy. However, Eq. 9 has the advantage of 279 incorporating the ethanol volume, $\mathrm{x}$.

\subsection{Bulk etch rate}

Experimental bulk etch rates for PADC SSNTD in the extended 283 concentrations range of $\mathrm{NaOH}(2-22 \mathrm{~N})$ and added ethanol volumes of $(0,1,2$ and $2843 \mathrm{~mL}$ ) in $8 \mathrm{~mL}$ of $\mathrm{NaOH}$ aqueous solutions are illustrated in Fig. 5. Experimental 
285

286

287

288

289

290

291

292

293

294

295

296

297

298

299

300

301

302

303

304

uncertainty or error bars $(\approx 15 \%)$ is relatively high. It represents the standard deviation of the measured fission fragment diameters, $\mathrm{D}_{\mathrm{ff}}$. This higher uncertainty may be accepted in terms of the manual track diameter measurements, extended concentration range, highly active and strong etching process implemented.

Arrhenius-like model successfully reproduce the experimental data in the extended molarity range, as shown in Fig. 5. The best fitting parameters are: $\alpha=0.05, \mathrm{DF}=10$, and $\chi^{2}<18.307$. Table 3 compiles the fitting parameters of the Arrhenius-like model. The degree of fitting is slightly degraded with increasing amount of ethanol and $\mathrm{NaOH}$ concentration. Considering physical data of bulk etch rates and Arrhenius fitting, the bulk etch kinetics can be explained chemically based on collision theory. During etching process, etching species in the etching solution collide with the molecules and atoms of the PADC detector with a range of energies which is dependent on the etching temperature. Etching reaction would take place if energies of colliding species are greater than activation energy of etching $(\varepsilon)$. The evaluated activation energies $(\varepsilon)$ are given in Table 3. The mean value $0.676 \mathrm{eV}$ (with deviation $\pm 0.023 \mathrm{eV}$, i.e., $<3.5 \%$ ) remains in agreement with previous resulted, reported in [15]. The activation energy of etching is weakly dependent (or almost independent) on the amount of ethanol added to the solution. This proves that etching process and chemical reaction rate within such extended concentration range is still at equilibrium. 
prediction to bulk etch rates of the extended concentration range incorporated with the experimental data. Fitting parameters of multi-hit models are given in Table 4. Inspecting Fig. 6 and Table 4 one can conclude that multi-hit model can reproduce bulk etch rate with good accuracy. Activation energy, $\varepsilon$ deduced by multi-hit model is less than previously reported value $(\approx 0.70 \mathrm{eV})[2,15,19]$ however, still 311 have the same order of magnitude. Values of number of hits, $v$ required for activating the sensitive volume of the polymer were 2 for 0 ethanol and 1 in the presence of ethanol as expected. This is one advantage for the multi-hit model where this number of hits, $v$ is another indicator about the etchant activity. As $v$ 315 decreases (=1) for ethanol solution, as the etchant activity probably increases 316 compared to $v=2$ for soft etching.

Bulk etch rates can also be predicted using an equation with only two 318 adjusting parameters [5]. This simple equation can reproduce the bulk etch rate 319 with accuracy where the best fitting parameters are: $\alpha=0.05, \mathrm{DF}=10$, and $\chi^{2}<$ 320 18.307 as given in Table 5 and illustrated in Fig. 7.

321 Experimental bulk etch rate and the non-linear fit using Eq. 10\&11 for the limited $322(2-10 \mathrm{~N})$ and extended molarity are shown in Fig. 8 and 9, respectively. The new 323 equations are predicting the bulk etch rate with the same high accuracy as 
illustrated in Tables $6 \& 7$. The different adjusting parameters $Q, i, j, U, a_{1}, a_{2}$ and $325 \mathrm{a}_{3}$ of equations $10 \& 11$ are compiled. The adjusting parameters are showing slight 326 dependence on $\mathrm{C}$ and $\mathrm{x}$. Of course, the $27 \%$ ethanol content $(3 \mathrm{~mL})$ data shows 327 higher $\chi^{2}$ value compared to the other ethanol volumes. However, it is statistically accepted. This is expected in terms of bulk etch rate has been duplicated compared to the closest ethanol volume of $20 \%$. The best fitting parameters are: $\alpha=0.05$, $\mathrm{DF}=4, \chi^{2}<9.488$ and $\alpha=0.05, \mathrm{DF}=10, \chi^{2}<18.307$ for the limited and extended concentration ranges. By the goodness of the fitting curves in comparison with the well-known models (Arrhenius and Multi hit) the validity of suggested empirical formula has been determined.

In the previous paragraphs, the different equations for bulk etch rate were studied individually. All the equations were succeeded to reproduce the bulk etch rate as depicted in Fig. 10 but with different accuracy Tables 3-7. However, Eq. 11 is more advantageous since it adds both $\mathrm{NaOH}$ molarity and ethanol fraction as etching parameter. Eventually, this equation can be applied to other SSNTDs and chemical etchants, such as $\mathrm{KOH}$.

Rigorous bulk etch rate $\mathrm{V}_{\mathrm{b}}$ of $\mathrm{PADC}$ in $\mathrm{NaOH} /$ ethanol compared to $\mathrm{NaOH} /$ water and lowering etching time, $\mathrm{t}_{\mathrm{e}}$ can be attributed to the fact that media 342 containing methanol or ethanol has smaller dielectric constant. Attraction forces 343 between electrical charges are enhanced in comparison to pure water. Therefore, it 
is likely that addition of alcohols in $\mathrm{NaOH}$ aqueous solution may partly lower the relative static permittivity of the etchant and thus enhances hydroxide ion reactivity on polar groups (carbonate ester groups).

\subsection{Reciprocal bulk etch rate}

PADC bulk and track etch rate variation with depth up to $\approx 80 \mu \mathrm{m}$ was intensively investigated where strong etching allows successive etching effectively with reasonable etching time. The variation in $\mathrm{V}_{\mathrm{b}}$ and $\mathrm{V}_{\mathrm{t}}$ with depth for swift $\mathrm{Si}$ ion are illustrated in Fig. 11. It was found that bulk etch rate is slightly increasing with depth in agreement with Fujii and Nishimura, 1986 [35]. Simultaneously, the track shaped etch-pits were measured for limited number of cones, and the corresponding track etch rate $V_{t}$ was determined. The track etch rate $V_{t}$ is found to be almost constant as expected for swift heavy ions passes through the bulk of SSNTD.

Detector sensitivity, $\mathrm{V}$ for $\mathrm{Si}$ ion was determined and normalized to value achieved at the first etched-off layer of a detector where $V=\frac{\mathrm{V}_{t}}{\mathrm{~V}_{\mathrm{b}}}$. Variation in normalized sensitivity as a function of the removed layer $\mathrm{h}$ is presented in Fig. 12. One can observe that the detector sensitivity decreases with depth and reaches between $60-80 \%$ and becomes more stable at depth $25 \mu \mathrm{m}$ inwards. This reduced 
363

364

sensitivity with depth is due to the slight increase in $V_{b}$ while $V_{t}$ is almost constant. The variation of $\mathrm{V}_{\mathrm{b}}$ is an effect, probably specific for long etching time periods as already mentioned in literature [35] (and references therein) in the case of a 2 $\mathrm{GeV} /$ nucleon iron nucleus track etched for more than 20 hours. The reasons for $\mathrm{V}_{\mathrm{b}}$ (and hence V) variation with depth may be due to a property of used plastic, structural inhomogeneity in the detector material linked with its curing process during fabrication and finally the successive etching process that follows heating and drying of the detector sample many times. It was mentioned by Fujii and Nishimura [35] that "most of the thick CR-39 sheets commercially available show the depth dependence". However, this phenomenon deserves further investigation.

Experimental and calculated reciprocal bulk etch rate with normalized depth (total depth, $\mathrm{z}=1$ ) are illustrated in Fig. 13 where the best fitting of Eq. 12 was obtained at $f=0.04$ and $g=0.07$. Prolonged etching with the amount of bulk-etch exceeding $80 \mu \mathrm{m}$ is necessary for producing swift heavy ions thick track membrane [36] and study the track wall curvature development with removed layer through the entire detector depth. Eq. 12 is fundamental for simulating the etched track profiles and the shape of the track curvature developed with depth inside the polymer and it can describe the reciprocal $\mathrm{V}_{\mathrm{b}}$ as a function of $(\mathrm{z})$ for soft etching conditions as well. 


\section{Conclusions}

Two empirical equations were proposed for bulk etch rate estimation. Both

385 equations were applied to soft and strong etching. A reasonable reproduction of bulk etch rate was found at both limited and extended concentration range with different ethanol volumes. Validity of suggested empirical formula has been proved by goodness of the curves compared to Arrhenius and Multi-hits models. Eq. 10 is using etchant concentration like literature equations. Eq. 11 has the advantage that it reproduces the bulk etch rate as a function of both $\mathrm{NaOH}$ concentration and ethanol fraction simultaneously. This equation can be extended to other SSNTDs, and another etchant as well.

Two equations were suggested to calculate the etching time as a function of molarity and molarity with ethanol volume. The reduction in etching time can save considerable time in many applications.

Higher $\mathrm{V}_{\mathrm{b}}$ and lower $\mathrm{t}_{\mathrm{e}}$ of PADC can be explained by better solubility of etch 397 product in ethanol than in water. Ethanol medium provides smaller dielectric 398 constant and thus improves the attraction forces between electrical charges. Lower 399 static permittivity of ethanol etchant enhances hydroxide reactivity on carbonate 400 ester groups. 
Deep (up to $80 \mu \mathrm{m}$ ) bulk etch rate and deep detector sensitivity were 402 investigated. $\mathrm{V}_{\mathrm{b}}$ shows slight increase while $\mathrm{V}$ show slight decrease with depth. 403 Detector sensitivity is slightly decreasing with depth reaching 60-80\% after $25 \mu \mathrm{m}$

404 405 406

414 the detector molecules and obtain the release time of a given thickness in 415 connection with the etching time. 


\section{Acknowledgment}

423 The authors are grateful to the unknown reviewers for their constructive 424 suggestions. The authors are very thankful to Ms Eman Bebers for providing the 425 data from her M.Sc thesis, Prof. A. Khafagy, Prof. of Physics, Faculty of Science, 426 Menoufia University and Mr. Atta H. Lakho, of GBDC, Karachi for English 427 revising and editing the manuscript. Mushtaq Abed Al-Jubbori is grateful to the 428 University of Mosul/ College of Education for Pure Sciences.

\section{Figures Caption}

430 Fig. 1 Ester group hydrolysis in PADC CR-39 and the cleavage of ester linkage caused by hydroxide ion.

432 Fig. 2 Stages of the hydroxyl attack on the carbonyl during the etching process.

434 Fig. 3 The possible positions of the cleavage and the yielded etching outputs.

435 Fig. 4 Eqs. 8 and 9 prediction to the etching time necessary to obtain $\mathrm{D}_{\text {ff }} \approx 18$ $\mu \mathrm{m}$ using different $\mathrm{NaOH}$ molarity for soft and strong etching, 
respectively. Eq. 9 has the advantage of incorporating the ethanol volume, $\mathrm{x}$.

Fig. 5 Arrhenius equation fit of bulk etch rate in extended $\mathrm{NaOH} / \mathrm{ethanol}$ concentration range.

Fig. 6 Multi hit model of MHM-M8 and MHM-M15 fit of bulk etch rate in extended $\mathrm{NaOH} /$ ethanol concentration range.

Fig. 7 Al-Jubbori-2016 equation fit of bulk etch rate in extended $\mathrm{NaOH} /$ ethanol concentration range.

Fig. 8 Prediction of the newly suggested equations (Eq. 10 and Eq. 11) to bulk etch rate for the limited $(2-10 \mathrm{~N}) \mathrm{NaOH}$ concentration range mixed with different ethanol volume.

Fig. 9 Prediction of the newly suggested equations (Eq. 10 and Eq. 11) to bulk etch rate for the extended $(2-22 \mathrm{~N}) \mathrm{NaOH}$ concentration range mixed with different ethanol volume.

Fig. 10 Experimental bulk etch rate and the corresponding calculated ones using Arrhenius, MHM-M8, Al-Jubbori-2016 and the new suggested Eq. 11 as a function of $\mathrm{NaOH}$ concentration and different ethanol volumes. 
455 Fig. 11 The variation in the bulk and track etch rate with removed layer (depth) for Si swift heavy ion.

457 Fig. 12 PADC sensitivity (V) normalized to value, achieved at the first

Fig. 13 Experimental and calculated reciprocal bulk etch rate with normalized depth (total removed layer, $\mathrm{z}=1$ ).

462

464 Table 1 Fitting parameters for etch time formula (Eq. 8).

465 Table 2 Fitting parameters for etch time formula (Eq. 9).

466 Table 3 Arrhenius equation fitting parameters for the extended $\mathrm{NaOH}$ concentration and different ethanol volume at $\mathrm{B}=1.25 \times 10^{9}$.

468 Table 4 MHM-M8 and MHM-M15 fitting parameters for the extended $\mathrm{NaOH}$ concentration and different ethanol volume at $\mathrm{B}=1.25 \times 10^{9}$. concentration and different ethanol volume. 
472 Table 6 New equation (Eq. 10) fitting parameters for limited and extended $\mathrm{NaOH}$ concentration range at different ethanol volume.

474 Table 7 New equation (Eq. 11) fitting parameters for limited and extended $\mathrm{NaOH}$ concentration range at different ethanol volume.

476

477

478

479

480

\section{References}

481 [1] M. Fromm, F. Membrey, A. Chambaudet, R. Saouli, Proton and alpha track 482 profiles in CR39 during etching and their implications on track etching models.

483 Nucl. Track Radiat. Meas. 19 (1991) 163-168.

484 Doi: 10.1016/1359-0189(91)90165-E

485 [2] E.M. Awad, V.A. Ditlov, M. Fromm, D. Hermsdorf, Description of the bulk 486 etching rate of CR-39 by an extended Arrhenius-like law in increased intervals of 487 temperature and etchant concentration, Radiat. Meas. 44 (2009) 813-820. 488 Doi: $10.1016 /$ j.radmeas.2009.10.087 
489

490

491

492

493

494

495

496

497

498

499

500

501

502

503

504

505

506

[3] S. Kodaira, K. Morishige, H. Kawashima, H. Kitamura, M. Kurano, N. Hasebe,

Y. Koguchi, W. Shinozaki, K. Ogura, A performance test of a new high-surfacequality and high-sensitivity CR-39 plastic nuclear track detector - TechnoTrak.

Nucl. Instrum. Meth. B 383 (2016) 129-135.

Doi.10.1016/j.nimb.2016.07.002

[4] E.M. Awad, A.A. Soliman, Y.S. Rammah, Alpha particle spectroscopy for CR39 detector utilizing matrix of energy equations. Phys. Lett. A $369(5,6)(2007)$ 359-366.

Doi: 10.1016/j.physleta.2007.05.011

[5] M.A. Al-Jubbori, A parameterization of the chemistry-normality dependence of bulk etch rate in a CR-39 detector. App. Radiat. Iso. 118 (2016) 228-231.

\section{Doi: 10.1016/j.apradiso.2016.09.022}

[6] A.A. Azooz, M.A. Al-Jubbori, Alpha particles energy estimation from track diameter development in a CR-39 detector, App. Radiat. Iso. 115 (2016) 74-80.

\section{Doi: $10.1016 /$ j.apradiso.2016.06.008}

[7] A.A. Azooz, D. Hermsdorf, M.A. Al-Jubbori, New approach of modeling charged particles track development in CR-39 detectors. Radiat. Meas. 58 (2013) 94-100. 
508 [8] E.M. Awad, S. Hassan, E. Bebers, Y.S. Rammah, Bulk etch rate for PADC CR50939 at extended concentration range of $\mathrm{NaOH}$ mixed with ethanol and etchant 510 viscosity study. Nucl. Instrum. Meth. B 464 (2020) 45-55. 511 Doi:10.13140/RG.2.2.10854.78409

513 rates for poly-allyl-diglycol carbonate (PADC) and cellulose nitrate in a broad 514 range of concentration and temperature of $\mathrm{NaOH}$ etching solution. Radiat. Meas. $515 \quad 42(2007) 1-7$.

516 Doi: 10.1016/j.radmeas.2006.06.009

517 [10] M.A. Al-Jubbori, V-Function to Investigate Tracks of the Alpha Particle 518 Irradiated CR-39 Detector, Radiat. Meas., 136 (2020) 106388.

519 Doi: 10.1016/j.radmeas.2020.106388

520 [11] Matiullah, S. Rehman, S. Rehman, W. Zaman, Discovery of new etchants for

521 CR-39 detector. Radiat. Meas. 39 (2005) 337-343.

522

Doi: 10.1016/j.radmeas.2004.06.012

523

[12] Y.S. Rammah, E.M. Awad, O. Ashraf, Makrofol DE 1-4 as alpha dosimeter:

524

Optimum etching conditions. Radiat. Phys. Chem., 151(2018) 19-24. 
526 [13] V. Chavana, P.C. Kalsib, S.W. Honga, V.K. Manchandab, A new chemical 527 etchant for the development of alpha tracks in CR-39 solid state nuclear track

528 detector. Nucl. Instrum. Meth. B. 462(2020) 82-89.

529 Doi:10.1016/j.nimb.2019.10.033

530 [14] G. Somogyi, I. Hunyadi, Etching properties of the CR-39 polymeric nuclear 531 track detector. Nucl. Track Det. (1980) 443-452.

532 Doi: 10.1016/B978-0-08-025029-8.50055-X

533 [15] E.M. Awad, H.M. El-Samman, Activation energy of etching for CR-39 as a 534 function of linear energy transfer of the incident particles. Radiat. Meas. 31 (1999) $535 \quad 109-114$.

536 Doi: 10.1016/S1350-4487(99)00123-7

537 [16] S. Kodaira, D. Nanjo, H. Kawashima, N. Yasuda, T. Konishi, M. Kurano, H. 538 Kitamura, Y. Uchihori, S. Naka, S. Ota, Y. Ideguchi, Mass spectrometry analysis 539 of etch products from CR-39 plastic irradiated by heavy ions. Nucl. Instrum. Meth. 540 B 286 (2012) 229-232. 
542 [17] V. Ditlov, Formation model of bulk etching rate for polymer detectors. Radiat. 543 Meas. 40 (2005) 240-248.

544 Doi: 10.1016/j.radmeas.2005.06.010

545 [18] E.M. Awad, Applicability of the multi-hit model to calculate the track etch 546 rate in $\mu \mathrm{m}$-scale in CR-39 detectors. Radiat. Eff. Def. Solid 158 (2003) 539-550.

547 Doi: 10.1080/1042015031000099780

548 [19] E.M. Awad, Multi-hit model on CR-39, DAM-ADC and LR-115 SSNTDs:

549 Statistical and comparative study. Radiat. Meas. 105 (2017) 70-78.

550 Doi: $10.1016 /$ j.radmeas.2017.08.001

551 [20] M. Fromm, E. M. Awad, V. Ditlov, Many-hit model calculations for track 552 etch rate in CR-39 SSNTD using confocal microscope data. Nucl. Instrum. Meth. 553 B $226(2004) 565-574$.

554 Doi: 10.1016/j.nimb.2004.07.004

555 [21] V. A. Ditlov, E. M. Awad, D. Hermsdorf, M. Fromm, Interpretation of the 556 bulk etching process in LR-115 detectors by the many-hit model. Radiat. Meas. $557 \quad 43(2008)$ S82-S86.

558 Doi: 10.1016/j.radmeas.2008.03.071 
559 [22] V.A. Ditlov, E.M. Awad, M. Fromm, D. Hermsdorf, The Bragg-peak studies

560 in CR-39 SSNTD on the basis of many-hit model for track etch rates. Radiat.

561 Meas. $40(2-6)(2005)$ 249-254.

562 Doi.10.1016/j.radmeas.2005.03.009

563 [23] M. Fromm, F. Membrey, A. Chambaudet, R. Saouli, A. El-Rahamany, A 564 study of CR39 bulk etch properties under various temperature and concentration 565 conditions to modelized the dissolution rate. Nucl. Track Radiat. Meas. 19 (1991) $566 \quad 169-170$.

567 Doi:10.1016/1359-0189(91)90166-F

568 [24] B.G. Cartwright, E.K. Shirk, P.B. Price, A nuclear-track-recording polymer of 569 unique sensitivity and resolution. Nucl. Instrum. Meth. 153 (1978) 457.

570 Doi: 10.1016/0029-554X(78)90989-8

571 [25] J. Szabó, J.K. Pàlfalvi, Calibration of solid state nuclear track detectors at high

572 energy ion beams for cosmic radiation measurements: HAMLET results.

573 Nucl. Instrum. Meth. A 694 (2012) 193-198.

574 Doi.10.1016/j.nima.2012.08.010 
575 [26] K.C.C. Tse, D. Nikezic, K.N. Yu, Comparative studies of etching mechanisms 576 of $\mathrm{CR}-39$ in $\mathrm{NaOH} / \mathrm{H} 2 \mathrm{O}$ and $\mathrm{NaOH} /$ ethanol. Nucl. Instrum. Meth. B 263 (2007) $577 \quad 300-305$.

578 Doi:10.1016/j.nimb.2007.04.307

579 [27] A. Li, S.H. Yalkowsky, Solubility of organic solutes in ethanol-water 580 mixtures. Jour. Pharma. Sci. 83(12) (1994) 1735-1740.

581 Doi: $10.1002 / j p s .2600831217$

582 [28] D. Nikezic, K.N. Yu, Formation and growth of tracks in nuclear track 583 materials. Mate. Scie. Eng.: R: Reports 46 (2004) 51-123.

584 Doi: 10.1016/j.mser.2004.07.003

585 [29] E.M. Awad, M.A. Rana, M.A. Al-Jubbori, Bulk etch rates of CR-39 at high 586 etchant concentrations: diffusion-limited etching, NUCL SCI TECH 31 (2020) 587118.

588 https://doi.org/10.1007/s41365-020-00830-6

589 [30] M. Fromm, Light MeV-ions etching studies in a plastic track detector. Radiat. 590 Meas. 40 (2005) 160-169.

591 Doi: 10.1016/j.radmeas.2005.04.028 
592

593

594

595

596

597

598

599

600

601

602

603

604

605

606

607

608

[31] T. Yamauchi, H. Ichijo, K. Oda, B. Doerschel, D. Hermsdorf, K. Kadner, F.

Vaginay, M. Fromm, A. Chambaudet, Inter-comparison of geometrical track parameters and depth dependent track etch rates measured for Li-7 ions in two types of CR-39. Radiat. Meas. 34 (2001) 37-43.

Doi: 10.1016/S1350-4487(01)00117-2

[32] E.M. Awad, Direct determination of track etch rate and response of CR-39 to normal incidence high-energy heavy ions. Radiat. Meas. 33 (2001) 855-858.

\section{Doi.org/10.1016/S1350-4487(01)00098-1}

[33] S. Abdelaal, A.M. Abdelhady, H.H. Tokhy, A.M. Eid, Y.S. Rammah, E.M.

Awad, E.K. Elmaghraby, Breeding behavior of radiation-induced effects in organic materials and their possible use as radiation dosimeters.

J. Phys. Chem. of Solids 150 (2021) 109814.

Doi.org/10.1016/j.jpcs.2020.109814

[34] A. Malinowska, M. Jaskóla, A. Korman, A. Szydłowski, K. Malinowski, B. Sartowska, M. Kuk, Change in the sensitivity of PM-355 track detectors for protons after long-term storage. Radiat. Meas. 93 (2016) 55-59

Doi.org/10.1016/j.radmeas.2016.04.007 
609 [35] M. Fujii, J. Nishimura, Generalized etch-pit equations and their application to 610 analyses of tracks in CR-39 with depth dependent etching properties. Nucl. Track 611 Radiat. Meas. 11 (1-2) (1986) 25-33.

612 Doi: 10.1016/1359-0189(86)90016-6

613 [36] E.M. Awad, S. Hassan, E. Bebers, Y.S. Rammah, Strong etching investigation 614 on PADC CR-39 as a thick track membrane with deep depth profile study. Radiat. 615 Phys. Chem. 177 (2020) 109104.

616 Doi: 10.1016/j.radphyschem.2020.109104

617

618 